\title{
PENGARUH LIMBAH ASBES DAN FLY ASH DALAM PEMBUATAN KUSEN BETON
}

\author{
M. Shofi'ul Amin', Enes Ariyanto S. ${ }^{2}$, Zulis Erwanto ${ }^{3}$, Aris Purwanto ${ }^{4}$ \\ ${ }^{1}$ Jurusan Teknik Sipil Politeknik Negeri Banyuwangi, Banyuwangi, 68461 \\ Email:1shofiul@poliwangi.ac.id, ${ }^{2}$ enesariyanto.sandi@gmail.com, ${ }^{3}$ zulis.poliwangi@gmail.com, \\ 4arisbount@gmail.com
}

\begin{abstract}
Demand for building materials such as lumber keep on increase, especially as materials for door frames, vents, roofing and other construction in residential construction. Concrete frame was one alternatives that could be used as a door frame. Along with the advancement on development of concrete sills, many developed of design from concrete frame, but the utilization of waste as a mixture of the concrete frame has not been done. This research made mortar as specimen using additional material asbestos waste and fly ash. The percentage of mixing was $1 p c: 5 P s+(30 \%$ waste). The results of research gained the density asbestos waste and fly ash were $2.08 \mathrm{gr} / \mathrm{cm}^{3}$ and $2.58 \mathrm{gr} / \mathrm{cm}^{3}$. The compressive strength of mortar with the addition of asbestos waste has a lower compressive strength that was the age of 7, 14, 21, and 28 day compressive strength of mortar respectively $14.67 \mathrm{~kg} / \mathrm{cm}^{2}$, $26.67 \mathrm{~kg} / \mathrm{cm}^{2}, 90.67 \mathrm{~kg} / \mathrm{cm}^{2}$, and $104.00 \mathrm{~kg} / \mathrm{cm}^{2}$. While the value of the compressive strength of mortar with a mixture of fly ash waste at ages $7,14,21$, and 28 days respectively were $16.00 \mathrm{~kg} / \mathrm{cm}^{2}, 42.67$ $\mathrm{kg} / \mathrm{cm}^{2}, 112.00 \mathrm{~kg} / \mathrm{cm}^{2}$, and $2130.67 \mathrm{~kg} / \mathrm{cm}^{2}$.
\end{abstract}

Key words : Door frame of concrete, asbestos waste, fly ash, mortar

\begin{abstract}
ABSTRAK
Kebutuhan material bangunan seperti kayu terus meningkat terutama sebagai bahan pembuatan kusen pintu, ventilasi, konstruksi atap dan lain sebagainya dalam kontruksi perumahan. Kusen beton merupakan salah satu alternatif yang bisa digunakan sebagai kusen pintu. Seiring dengan kemajuan perkembangan mengenai kusen beton, banyak sekali dikembangkan desain dari kusen beton. Pemanfaatan limbah asbes dan fly ash bertujuan mengurangi komposisi semen untuk campuran pembuatan kusen beton. Pada penelitian ini berbentuk mortar dengan menggunakan bahan tambah limbah asbes dan fly ash. Prosentase pencampuran 1Pc : 5 Ps + (30\% limbah). Pengujian yang dilakukan yaitu berat jenis, resapan pasir, kadar lumpur pasir, serta kuat tekan. Berdasarkan hasil penelitian yang didapatkan berat jenis limbah asbes sebesar $2,08 \mathrm{gr} / \mathrm{cm}^{3}$, dan berat jenis limbah fly ash $2,58 \mathrm{gr} / \mathrm{cm}^{3}$. Nilai kuat tekan mortar dengan tambahan limbah asbes memiliki kuat tekan yang lebih rendah yaitu pada umur 7, 14, 21, dan 28 hari kuat tekan mortar berturut - turut sebesar 14,67 $\mathrm{kg} / \mathrm{cm}^{2}, 26,67 \mathrm{~kg} / \mathrm{cm}^{2}, 90,67 \mathrm{~kg} / \mathrm{cm}^{2}$, dan $104,00 \mathrm{~kg} / \mathrm{cm}^{2}$. Sedangkan nilai kuat tekan mortar dengan campuran limbah fly ash pada umur 7,14,21, dan 28 hari berturut - turut sebesar 16,00 kg/cm², 42,67 $\mathrm{kg} / \mathrm{cm}^{2}, 112,00 \mathrm{~kg} / \mathrm{cm}^{2}$, dan $130,67 \mathrm{~kg} / \mathrm{cm}^{2}$.
\end{abstract}

Kata kunci : Kusen beton, limbah asbes, fly ash, mortar

\section{PENDAHULUAN}

Perkembangan pembangunan dengan kebutuhan material bangunan seperti kayu terus meningkat terutama sebagai bahan pembuatan kusen pintu, ventilasi, konstruksi atap dan lain sebagainya dalam kontruksi perumahan. Sedangkan produksi kayu sangat terbatas, selain harganya yang mahal, juga berakibat terganggunya lingkungan. Peningkatan akan kebutuhan bangunan harus disikapi dengan pemanfaatan dan penemuan alternative bahan bangunan baru yang mempunyai kualitas yang baik. Sekarang banyak dikembangkan bahan material pengganti kayu seperti beton untuk konstruksi gedung dan 
perumahan yang salah satunya dibuat menjadi kusen beton.

Kusen beton merupakan salah satu alternative yang digunakan dalam pemasangan kusen pintu atau ventilasi. Penggunaan kusen beton saat ini sudah menyebar luas hingga kepelosok desa namun, harganya masih terlalu tinggi untuk masyarakat. Untuk menekan harga kusen beton yang terlalu mahal, perlu dilakukan inovasi pemanfaatan limbah untuk kusen beton dan memiliki kualitas yang tidak jauh beda. Seiring dengan kemajuan perkembangan mengenai kusen beton, banyak sekali dikembangkan bentuk desain dari kusen beton, tetapi pemanfaatan limbah sebagai campuran dari kusen beton belum banyak dilakukan.

PT. Pabrik Kertas Basuki Rachmat Banyuwangi menggunakan batu bara untuk bahan bakar pengolahan kertasnya. Sehingga menghasilkan limbah hasil dari pembakaran tersebut berupa fly ash (abu terbang) yang banyak dan pemanfaatan limbah asbes PT. Timur Sejahtera Banyuwangi dalam proses produksinya banyak menghasilkan limbah asbes. Untuk itu perlu adanya upaya pengolahan limbah agar tidak berbahaya lagi, seperti pemanfaatan limbah asbes dan fly ash sebagai bahan campuran pembuatan kusen beton.

Pemanfaatan limbah asbes dan fly ash bertujuan mengurangi komposisi semen untuk campuran pembuatan kusen beton sehingga dapat mengurangi limbah asbes dan fly ash yang berbahaya terhadap lingkungan. Limbah asbes dan fly ash ini mengandung sifat pozzolan sehingga dirasa tepat sebagai campuran pembuatan kusen beton. Dengan bahan tambahan limbah untuk pembuatan kusen beton dapat menjadikan produk kusen beton yang bernilai lebih ekonomis. Penelitian ini dilakukan untuk menghasilkan kusen beton dengan mutu/kekuatan yang baik.

\section{METODE PENELITIAN}

Pelaksanaan penelitian ini diawali dengan menentukan konsep penelitian, lalu dilanjutkan studi pustaka, lalu pengumpulan material (pasir, semen, limbah asbes) setelah itu limbah asbes diuji pada ayakan no 200 terlebih dahulu agar mendapatkan material yang seragam. Kemudian pengujian limbah asbes, limbah Fly Ash dan pasir dilakukan pengujian berat jenisnya agar mengetahui karakteristik material tersebut. Kemudian pasir diuji resapan air. Selanjutnya uji kadar lumpur pasir. Setelah pengujian bahan selesai dilanjutkan menentukan komposisi campuran, dilanjutkan pembuatan mortar sesuai dengan komposisi yang direncanakan dan dilakukan pencetakan sampai pengujian berat volume,dan kuat tekan pada mortar. Setelah hasil uji sesuai dengan mutu mortar yang ditargetkan yaitu K 175 atau setara dengan (SNI) 03-6882-2002 tentang spesifikasi mortar untuk pekerjaan pasangan tipe (S) yaitu 12,4 Mpa, kemudian dilanjutkan dengan membuat Pemodelan Elemen Struktur Dengan SAP 2000 Versi 14.2.2 dan dikontrol, selanjutnya membuat produk kusen beton. Setelah itu membandingkan harganya di pasaran dan selesai.

\section{HASIL dan PEMBAHASAN}

Pembuatan mortar dalam penelitian ini adalah sebagai benda uji yang terdiri dari komposisi semen, fly ash, asbes, pasir dan air, dengan perbandingan campuran 1PC : 5PS, dan variasi masing - masing limbah30\% sebagai bahan pengganti dari semen. Mortardibuat menjadi 3 type antara lain mortar normal tanpa campuran limbah, mortar dengan campuran limbah asbes, dan mortar dengan campuran limbah fly 
ash.Adapun parameter pengujian meliputi pengujian agregat halus, pengujianlimbah dan pengujianmortar. Sifat dari masing - masing mortarakan diketahui setelah dilakukan perawatan selama umur 7, 14, 21 dan 28 hari.

\section{Limbah Asbes}

Tabel 1 menunjukkan bahwa asbes memilik berat jenis rata-rata sebesar $2,04 \mathrm{gr} / \mathrm{cm}^{3}$. Untuk berat jenis asbes ini tidak ada persyaratan khusus untuk nilai berat jenis asbes yang disyaratkan.

\section{Fly Ash}

Pengujian berat jenis fly ash ini diperlukan untuk mengetahui sifat karakteristiknya. Berat Hasil pengujian berat jenis fly ash akan disajikan pada Tabel 2.

Pengujian berat jenis fly ash didapatkan nilai rata-rata sebesar $2,58 \mathrm{gr} / \mathrm{cm}^{3}$. Sedangkan pada penelitian Sri Subekti dan Boedi Wibowotahun 2008 didapatkan berat jenis Fly Ash sebesar $2,63 \mathrm{gr} / \mathrm{cm}^{3}$. Untuk berat jenis fly ash tidak ada standart khusus, nilai berat jenis fly ash yang disyaratkan.

\section{Pembuatan Benda Uji Mortar}

Sebelum melakukan pembuatan benda uji mortar, terlebih dahulu menentukan komposisi campuran agar mortar yang dihasilkan sesuai dengan campuran yang telah direncanakan. Dalam penelitian ini menggunakan campuran 1PC : 5PS. Selanjutnya mengurangi komposisi semen dan diganti dengan penambahan limbah asbes dan fly ash sebanyak 0\% dan 30\% dalam tiap komposisinya.

Pada tabel 3, kebutuhan dalam 1 kali pembuatan 12 mortar membutuhkan pasir sebanyak 24kg, Semen 4,8kg dan air hingga campuran mortar homogen.

Tabel 4 menunjukkan kebutuhan dalam 1 kali pembuatan 12 mortar membutuhkan pasir sebanyak 24kg, semen 3,36kg, limbah (asbes dan fly ash) sebanyak 1,44 kg dan air hingga campuran mortar homogen.

\section{Berat Volume Mortar}

Pengujian berat volume dilakukan pada umur 28 hari, data yang didapatkan yaitu pada Gambar 1 menunjukkan grafik berat volume pada umur pengujian ke 28 hari untuk masingmasing variasi campuran, dapat disimpulkan mortar normal memiliki berat volume yang paling tinggi yaitu $1,85 \mathrm{gr} / \mathrm{cm}^{3}$ dibandingkan mortar fly ash $1,79 \mathrm{gr} / \mathrm{cm}^{3}$, dan mortar asbes 1,74 $\mathrm{gr} / \mathrm{cm}^{3}$, hal ini dipengaruhi oleh campuran dari limbah, semakin banyak campuran limbah maka berat volume mortar akan semakin ringan.

\section{Kuat Tekan Mortar}

Pengujian kuat tekan dilakukan pada umur 28 hari, data yang didapatkan yaitu pada Gambar 2 menunjukkan grafik kuat tekan pada umur pengujian ke 28 hari untuk masing - masing variasi campuran, mortar tanpa limbah memiliki kuat tekan $157,33 \mathrm{~kg} / \mathrm{cm}^{2}$ dan mortar fly ash $130,67 \mathrm{~kg} / \mathrm{cm}^{2}$, dibandingkan dengan mortar asbes memiliki kuat tekan terendah yaitu $104,00 \mathrm{~kg} / \mathrm{cm}^{2}$. Dari hasil kuat tekan yang di dapat pada umur 28 hari dapat disimpulkan bahwa dari perbandingan antara mortar dengan campuran limbah fly ash dan asbes, mortar dengan limbah fly ash mempunyai kuat tekan yang lebih tinggi sebesar 130,67 kg/ $\mathrm{cm}^{2}$ dan telah memenuhi kuat mutu yang disyaratkan SNI 03-6882-2002 tentang spesifikasi mortar untuk pekerjaan pasangan tipe (S) yaitu 12,4 MPa atau $\mathrm{K}-124,00 \mathrm{~kg} / \mathrm{cm}^{2}$. Hasil kuat tekan mortar dengan campuran limbah fly ash dan asbes yang merupakan benda uji dari produk kusen beton, hasil terbaik akan dibuat komposisi campuran dari produk kusen beton yaitu perbandingan 
campuran 1 pc : 5 ps + ( 30\% limbah fly ash sebagai pengganti semen).

\section{Permodelan Elemen Struktur SAP 2000 Versi 14.2.2}

Berikut hasil dari permodelan elemen struktur SAP 2000 versi 14.2.2 dan perhitungannya pada Gambar 3 dan Gambar 4.

$$
\begin{array}{ll}
2(1 / 2 \cdot \mathrm{q} 1 \cdot 0,75)+\mathrm{q} 1 \cdot 5 & =\mathrm{q} 2 \cdot 3 \\
0,75 \cdot \mathrm{q} 1+1,5 \cdot \mathrm{q} 1 & =3 \cdot \mathrm{q} 2 \\
2,25 \cdot \mathrm{q} 1 & =3 \cdot \mathrm{q} 2 \\
\frac{q 2}{q 1} & =\frac{2,25}{3} \\
& =0,75
\end{array}
$$

$$
\begin{aligned}
\mathrm{Q} 1 & =(4.0-2.2) \times 250 \mathrm{~kg} / \mathrm{m} 2 \times 0.75 \\
& =337.5 \mathrm{~kg} / \mathrm{m} \\
\mathrm{P} & =\mathrm{A}+\mathrm{B} \\
& =(250 \mathrm{~kg} / \mathrm{m} 2 \times(1 / 2 \times 1.1 \times 1.8))+ \\
& (250 \mathrm{~kg} / \mathrm{m} 2 \times(1 / 2 \times 1.1 \times 2.2)) \\
& =247.5+302.5 \\
& =550 \mathrm{~kg} \\
\mathrm{k} \quad & =\tan (45-(\alpha / 2))=0.61 \\
\mathrm{Q} 2 & =\mathrm{P} \times \mathrm{ka} \\
& =550 \mathrm{~kg} \times 0.61 \\
& =335.5 \mathrm{~kg}
\end{aligned}
$$

Momen yang bekerja :

$\mathrm{Mu}=94.12 \mathrm{~kg} \cdot \mathrm{m}=9412 \mathrm{~kg} \mathrm{~cm}$

Gaya lentur yang terjadi :

$$
\begin{aligned}
& \sigma_{\text {lentur }}=\frac{M \cdot y}{I x}<\mathrm{fc} \cdot 0,35 \\
& \sigma_{\text {lentur }}=\frac{9412 \times 7.5}{1 / 12 \times 6 \times 15^{3}}<130,67, \text { x } 0,35 \\
& \sigma_{\text {lentur }}=41.83 \mathrm{~kg} / \mathrm{cm}^{2}<45,73 \mathrm{~kg} / \mathrm{cm}^{2} \\
& \text { (kusen belum retak) }
\end{aligned}
$$

Gaya Aksial yang terjadi :

$\mathrm{Pu}=256 \mathrm{~kg}$

$$
\begin{aligned}
\sigma_{a k s i a l} & =\frac{P}{A}<0.75 \text { x fc' } \\
\sigma_{a k s i a l} & =\frac{256}{6 \times 15}<0.75 \times 130.67 \\
\sigma_{a k s i a l} & =2,84 \mathrm{~kg} / \mathrm{cm}^{2}<98.002 \mathrm{~kg} / \mathrm{cm}^{2}
\end{aligned}
$$

(kusen belum retak)
Hasil perhitungan kusen beton berbahan fly ash diatas dapat diambil kesimpulan bahwa dari momen lentur yang bekerja pada kusen beton, momen ultimite sebesar $41.83 \mathrm{~kg} / \mathrm{cm}^{2}$, nilainya lebih kecil dibandingkan dengan kuat tekan kusen yaitu sebesar $45,73 \mathrm{~kg} / \mathrm{cm}^{2}$, dan nilai tegangan aksial lebih kecil dibanding dengan kuat tekan kusen, sehingga kusen beton masih mampu menahan beban yang bekerja.

\section{Pembuatan Kusen Beton}

Sebelum melakukan pembuatan produk kusen beton, terlebih dahulu menentukan komposisi campuran agar kusen beton yang dihasilkan sesuai dengan campuran yang telah direncanakan. Dalam penelitian ini menggunakan campuran 1PC : 5PS dengan penggantian semen dengan limbah fly ash sebanyak 30\%. Kebutuhan dalam 1 kali pembuatan produk kusen beton dengan limbah fly ash membutuhkan pasir sebanyak 89,88 $\mathrm{kg}$, Semen 18,23 kg, fly ash 6,50 kg dan diberi besi tulangan Ø 8 sebanyak 2,21 $\mathrm{kg}$ atau 5,6 $\mathrm{m}$ sebagai penguat kusen beton. Cetakan yang digunakan memiliki ukuran $80 \mathrm{~cm} \mathrm{x} 200 \mathrm{~cm}$ x 6 cm x $15 \mathrm{~cm}$. pencetak kusen beton sekaligus proes pengecorannya dapat dilihat pada Gambar 5.

\section{Analisis Harga Kusen Beton}

Analisis harga ini dibuat sebagai perbandingan harga kusen beton dipasaran Banyuwangi dengan perhitungan harga dari kusen beton hasil penelitian.Satuan harga dan analisa diambil dari analisa dinas pekerjaan umum (PU) kabupaten Banyuwangi. Sempel harga kusen beton di Kabupaten Banyuwangi diambil dari lima wilayah yang berbeda antara lain wilayah utara, wilayah kota, wilayah tengah, wilayah barat, dan wilayah selatan. 
Hasil rencana anggaran biaya kusen beton dan perkiraan harga jual kusen beton hasil penelitian pada Tabel 5 serta harga kusen beton dipasaran Kabupaten Banyuwangi pada Tabel 6.

Berdasarkan perhitungan biaya yang disusun dapat diketahui anggaran biaya untuk kebutuhan bahan kusen beton sebesar Rp 104,434.44, untuk pekerja Rp 5,242.00, dan untuk kebutuhan peralatan Rp 15,000.00. Total biaya yang dibutuhkan untuk pembuatan 1 buah kusen beton ialah Rp 125,000.00.

Tabel 6 hasil dari survey harga kusen beton yang beredar di Kabupaten Banyuwangi diketahui bahwa harga kusen beton untuk tipe kusen pintu dengan ukuran $200 \mathrm{~cm}$ x $80 \mathrm{~cm}$ rata-rata Rp 142,000.00-. Sehingga dapat disimpulkan bahwa kusen beton dengan tambahan limbah fly ash dengan kusen beton normal yang diproduksi industri di Banyuwangi menghasilkan selisih harga relatif banyak dan untuk mutu kusen beton hasil penelitian mempunyai mutu K-130,67 yang masih memenuhi syarat (SNI) 03-6882-2002 tentang spesifikasi mortar untuk pekerjaan pasangan tipe (S) yaitu 12,4 Mpa atau $\mathrm{K}-124 \mathrm{~kg} / \mathrm{cm}^{2}$.

\section{KESIMPULAN}

Berdasarkan hasil dan pembahasan tersebut, maka disimpulkan antara lain :

1. Nilai kuat tekan mortar berbahan limbah yang dalam penelitian ini sebagai benda uji dari produk kusen beton, menunjukkan hasil kuat tekan mortar dengan limbah asbes memiliki kuat tekan yaitu pada umur 7, 14, 21, dan 28 hari kuat tekan mortar berturut - turut sebesar 14,67 $\mathrm{kg} / \mathrm{cm}^{2}, 26,67 \mathrm{~kg} / \mathrm{cm}^{2}, 90,67 \mathrm{~kg} / \mathrm{cm}^{2}$, dan $104,00 \mathrm{~kg} / \mathrm{cm}^{2}$. Sedangkan nilai kuat tekan mortar dengan campuran limbah fly ash pada umur 7,14,21, dan 28 hari berturut - turut sebesar
$16,00 \mathrm{~kg} / \mathrm{cm}^{2}, 42,67 \mathrm{~kg} / \mathrm{cm}^{2}, 112,00$ $\mathrm{kg} / \mathrm{cm}^{2}$, dan $130,67 \mathrm{~kg} / \mathrm{cm}^{2}$. Pada analisis SAP2000 dan perhitungan pembebanan kusen beton dengan tambahan limbah fly ash masih mampu menahan beban-beban yang bekerja akibat tembok. Sehingga hasil kusen beton dengan tambahan limbah fly ash relatif bisa digunakan.

2. Perbandingan harga antara kusen beton hasil penelitian dengan harga kusen beton industri di Banyuwangi yaitu harga kusen hasil penelitian sebesar Rp 125,000.-. Sedangkan harga kusen beton di Banyuwangi rata-rata sebesar $\mathrm{Rp}$ 142,000.terdapat selisih harga Rp 17,000.-.

\section{DAFTAR PUSTAKA}

[1] Ardiansyah, R. 2010. “ Fly Ash “ Manfaat Dan Kegunaannya, Artikel, Entry froam http//www.ronymedia.wordpress.co $\mathrm{m}$

[2] Danita L.N. 2014. Pemanfaatan Limbah Abu Sekam Dan Fly Ash Sebagai Pembuatan Campuran Pembuatan Paving Block Dengan Agregat Halus Kab. Banyuwangi, Proyek Akhir, Program Studi Teknik Sipil, Politeknik Negeri Banyuwangi, Banyuwangi.

[3] Soenarno, S.M 2011. Pengelolaan Limbah. Pendidikan Konservasi Alam, Yayasan Pelestarian Alam dan Kehidupan Liar Indonesia, Banyuwangi.

[4] Standart Nasional Indonesia (SNI) 03-6414-2002, Abu Terbang Dalam Campuran Beton.

[5] Standar Nasional Indonesia (SNI) 03-1973-1990, Metode Pengujian Berat Isi Beton.

[6] SK Standar Nasional Indonesia (SNI) S-04-1989-F, Semen Portland.

[7] SK Standar Nasional Indonesia (SNI) S-04-1989-F, Syarat Air Dalam Pembuatan Beton. 
[8] Standar Nasional Indonesia (SNI) 03-6820-2002, Tentang Agregat Halus.

[9] Standar Nasional Indonesia (SNI). 03-1970-2008, Tentang Berat Jenis dan Penyerapan Air Agregat Halus.
[10] Standar Nasional Indonesia (SNI). 03-4142-1996, Tentang Metode Pengujian Kadar Lumpur Agregat Halus.

[11] Standar Nasional Indonesia (SNI).03-6882-2002, Tentang Spesifikasi Mortar untuk Pekerjaan Pasangan.

Tabel 1. Pengujian Berat Jenis Asbes

\begin{tabular}{|c|c|c|c|c|c|}
\hline \multirow{2}{*}{ Keterangan } & \multirow{2}{*}{ Satuan } & \multicolumn{3}{|c|}{ No. Percobaan } & \multirow{2}{*}{$\begin{array}{c}\text { Rata- } \\
\text { rata }\end{array}$} \\
\hline & & I & II & III & \\
\hline (W1) Berat Asbes & gr & 50,00 & 50,00 & 50,00 & 50,00 \\
\hline Berat Picnometer & gr & 55,70 & 55,80 & 55,80 & 55,77 \\
\hline Berat Picnometer + Asbes & gr & 105,70 & 105,80 & 105,80 & 105,77 \\
\hline (W2) Berat Picnometer + Asbes + Minyak & gr & 168,60 & 164,00 & 162,90 & 165,17 \\
\hline (W3) Berat Picnometer + Minyak & gr & 135,00 & 134,70 & 135,60 & 135,10 \\
\hline Berat Jenis & $\mathrm{gr} / \mathrm{cm}^{3}$ & 2,44 & 1,93 & 1,76 & 2,04 \\
\hline
\end{tabular}

Sumber : Hasil Analisa

Tabel 2. Pengujian Berat Jenis Fly Ash

\begin{tabular}{|c|c|c|c|c|c|}
\hline \multirow{2}{*}{ Keterangan } & \multirow{2}{*}{ Satuan } & \multicolumn{3}{|c|}{ No. Percobaan } & \multirow{2}{*}{$\begin{array}{c}\text { Rata- } \\
\text { rata }\end{array}$} \\
\hline & & I & II & III & \\
\hline (W1) Berat Fly Ash & gr & 50,00 & 50,00 & 50,00 & 50,00 \\
\hline Berat Picnometer & gr & 55,70 & 52,60 & 40,1 & 49,5 \\
\hline $\begin{array}{l}\text { Berat Picnometer + Fly Ash } \\
\text { (W2) Berat Picnometer + Fly Ash + }\end{array}$ & gr & 105,70 & 102,6 & 90,10 & 99,50 \\
\hline Minyak & gr & 168,60 & 169,40 & 154,8 & 164,30 \\
\hline (W3) Berat Picnometer + Minyak & gr & 134,20 & 135,00 & 120,10 & 129,80 \\
\hline Berat Jenis & $\mathrm{gr} / \mathrm{cm}^{3}$ & 2,56 & 2,56 & 2,61 & 2.58 \\
\hline
\end{tabular}

Sumber : Data primer yang diolah

Tabel 3. Komposisi Mortar 1 PC : 5 PS dengan 0\% Limbah

\begin{tabular}{lcc}
\hline Keterangan & Satuan & Kebutuhan \\
\hline Semen & $\%$ & 16,67 \\
Pasir & $\%$ & 83,33 \\
Berat mortar Rata-rata & $\mathrm{kg}$ & 2,4 \\
semen/1mortar & $\mathrm{kg}$ & 0,4 \\
Kebutuhan Pasir/1mortar & $\mathrm{kg}$ & 2 \\
\hline Total Pasir & $\mathrm{kg}$ & 24 \\
\hline Total Limbah 0\% & $\mathrm{kg}$ & 0 \\
\hline Total semen & $\mathrm{kg}$ & 4,8 \\
\hline
\end{tabular}


Tabel 4. Komposisi Mortar 1 PC : 5 PS dengan 30\% Limbah

\begin{tabular}{lcc}
\hline Keterangan & Satuan & Kebutuhan \\
\hline Semen & $\%$ & 16,67 \\
Pasir & $\%$ & 83,33 \\
Berat mortar Rata-rata & $\mathrm{kg}$ & 2,4 \\
semen/1 mortar & $\mathrm{kg}$ & 0,28 \\
Kebutuhan Pasir/1mortar & $\mathrm{kg}$ & 2 \\
\hline Total Pasir & $\mathrm{kg}$ & 24 \\
\hline Total Limbah 30\% & $\mathrm{kg}$ & 1,44 \\
\hline Total semen & $\mathrm{kg}$ & 3,36 \\
\hline
\end{tabular}

Sumber : Data primer yang diolah

Tabel 5. Rencana Anggaran Biaya Pembuatan Kusen Beton

\begin{tabular}{|c|c|c|c|c|c|}
\hline A & TENAGA & SATUAN & $\begin{array}{l}\text { PERKIRAAN } \\
\text { KUANTITAS }\end{array}$ & $\begin{array}{l}\text { UPAH } \\
\text { OH/Hari }\end{array}$ & BIAYA \\
\hline 1 & Pekerja & $\mathrm{Oh} /(7 \mathrm{Jam})$ & 0,100 & Rp 52,420.00 & $5,242.00$ \\
\hline \multicolumn{5}{|c|}{ JUMLAH HARGA PEKERJAAN } & $5,242.00$ \\
\hline B & BAHAN & SATUAN & VOLUME & $\begin{array}{l}\text { HARGA } \\
\text { SATUAN }\end{array}$ & BIAYA \\
\hline 1 & Pasir & m3 & 0.0420 & Rp184,720.00 & $7,758.24$ \\
\hline 2 & Semen PC & $\mathrm{Kg}$ & 18.2280 & Rp $\quad 1,420.00$ & $25,883.76$ \\
\hline 3 & Fly Ash & $\mathrm{Kg}$ & 6.5000 & 333.33 & $2,166.64$ \\
\hline 4 & Besi Ø 8 & $\mathrm{Kg}$ & 2.2100 & Rp $12,980.00$ & Rp $\quad 28,685.80$ \\
\hline 5 & Engsel Pintu & $\mathrm{Bh}$ & 2.0000 & Rp $19,970.00$ & Rp $\quad 39,940.00$ \\
\hline \multicolumn{5}{|c|}{ JUMLAH HARGA PEKERJAAN } & Rp $104,434.44$ \\
\hline C & PERALATAN & SATUAN & $\begin{array}{c}\text { PERKIRAAN } \\
\text { KERJA }\end{array}$ & HARGA/ HR & BIAYA \\
\hline 1 & Cetakan Kusen & $\mathrm{Hr} /(12 \mathrm{jam})$ & 1 & Rp15,000.00 & Rp $\quad 15,000.00$ \\
\hline \multicolumn{5}{|c|}{ JUMLAH HARGA ALAT } & Rp 15,000.00jh \\
\hline \multicolumn{5}{|c|}{ JUMLAHA+ B + C } & Rp 124,858.44 \\
\hline \multicolumn{5}{|c|}{ DIBULATKAN } & Rp 125,000.00 \\
\hline
\end{tabular}

Sumber : Data sekunder yang diolah

Tabel 6. Daftar Harga Kusen Beton Di Wilayah Kabupaten Banyuwangi

\begin{tabular}{|c|c|c|c|c|c|}
\hline NO & $\begin{array}{c}\text { NAMA } \\
\text { INDUSTRI }\end{array}$ & LOKASI & $\begin{array}{c}\text { NAMA } \\
\text { PEMILIK }\end{array}$ & $\begin{array}{l}\text { TIPE KUSEN } \\
\text { BETON }\end{array}$ & $\begin{array}{l}\text { HARGA JUAL } \\
\text { PRODUK }\end{array}$ \\
\hline 1 & $\begin{array}{l}\text { Karya Mandiri } \\
\text { Dua }\end{array}$ & Wongsorejo & Busairi & Pintu 2 x 0,8 m & Rp 150,000.00 \\
\hline 2 & Sinar Jaya & Glagah & Abdul Rajis & Pintu 2 x 0,8 m & Rp 150,000.00 \\
\hline 3 & UD. Triyasa & Rogojampi & Rosid & Pintu 2 x 0,8 m & Rp 140,000.00 \\
\hline 4 & $\begin{array}{l}\text { UD. Sembilan } \\
\text { Jaya }\end{array}$ & Genteng & Rohman & Pintu 2 × 0,8 m & Rp $140,000.00$ \\
\hline 5 & Home industri & Cluring & Mulyono & Pintu 2 x 0,8 m & Rp 130,000.00 \\
\hline \multicolumn{5}{|c|}{ RATA-RATA HARGA JUAL KUSEN BETON } & Rp 142,000.00 \\
\hline
\end{tabular}




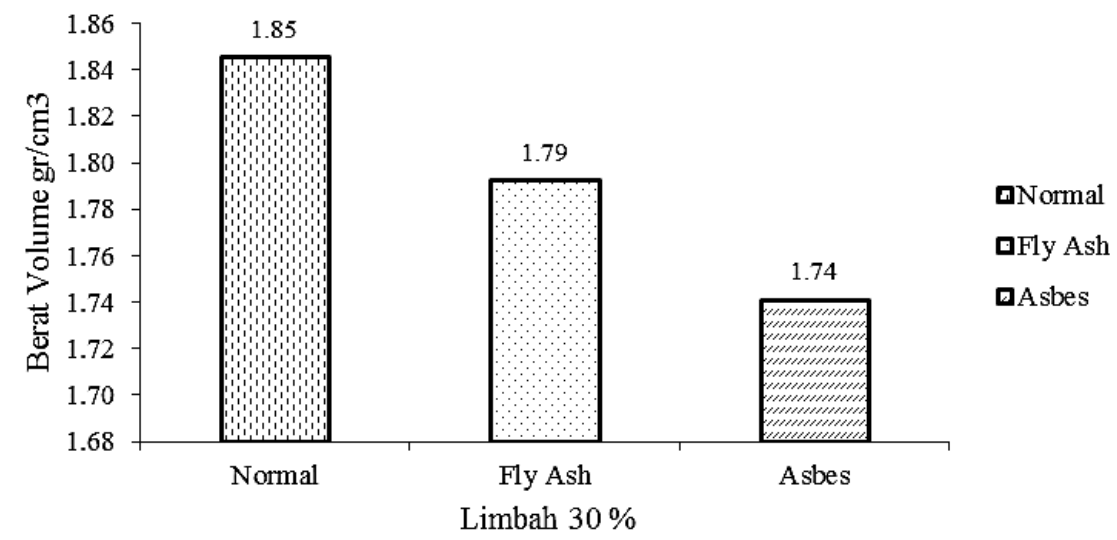

Gambar 1. Berat Volume Mortar Pada Umur 28 Hari

Sumber: Data primer yang diolah

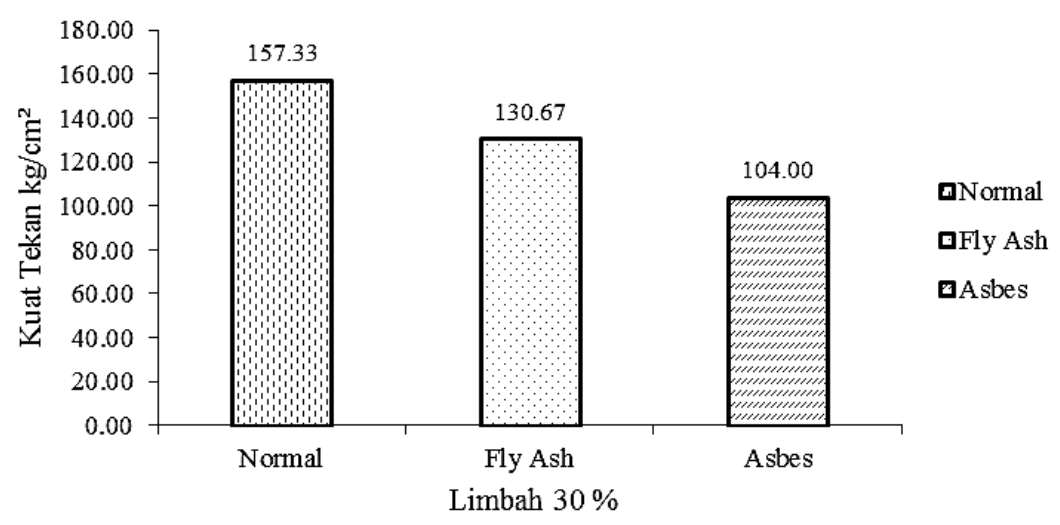

Gambar 2. Kuat Tekan Mortar Pada Umur 28 Hari

Sumber: Data primer yang diolah

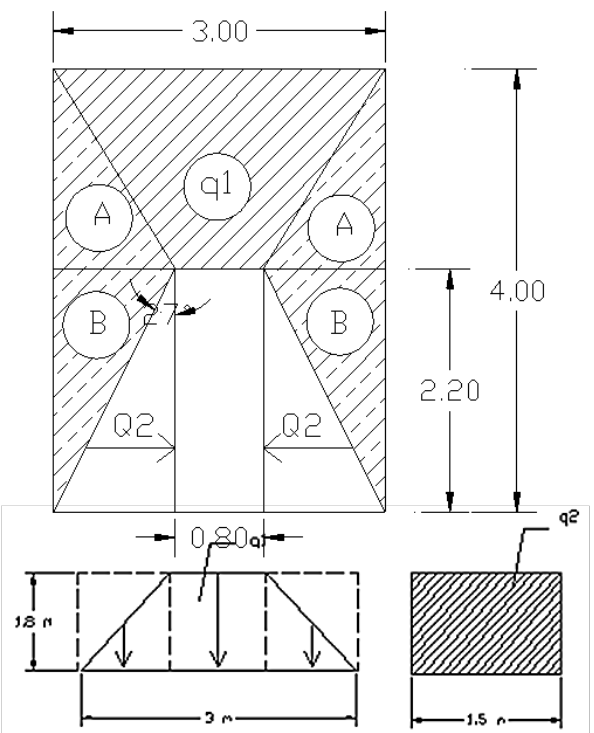

Gambar 3. Distribusi Pembebanan Pada Kusen Beton Sumber: Data primer yang diolah 

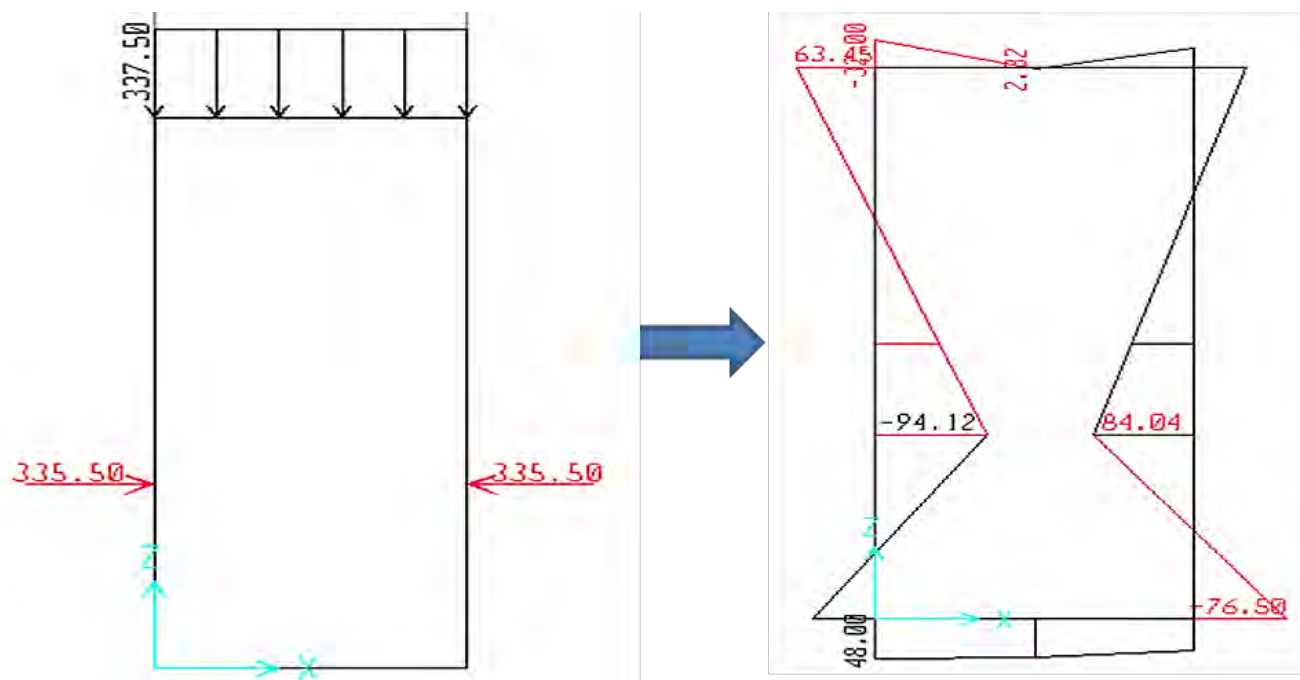

Gambar 4. Gambar Hasil Output SAP 2000 Versi 14.2.2

Sumber: Permodelan benda uji
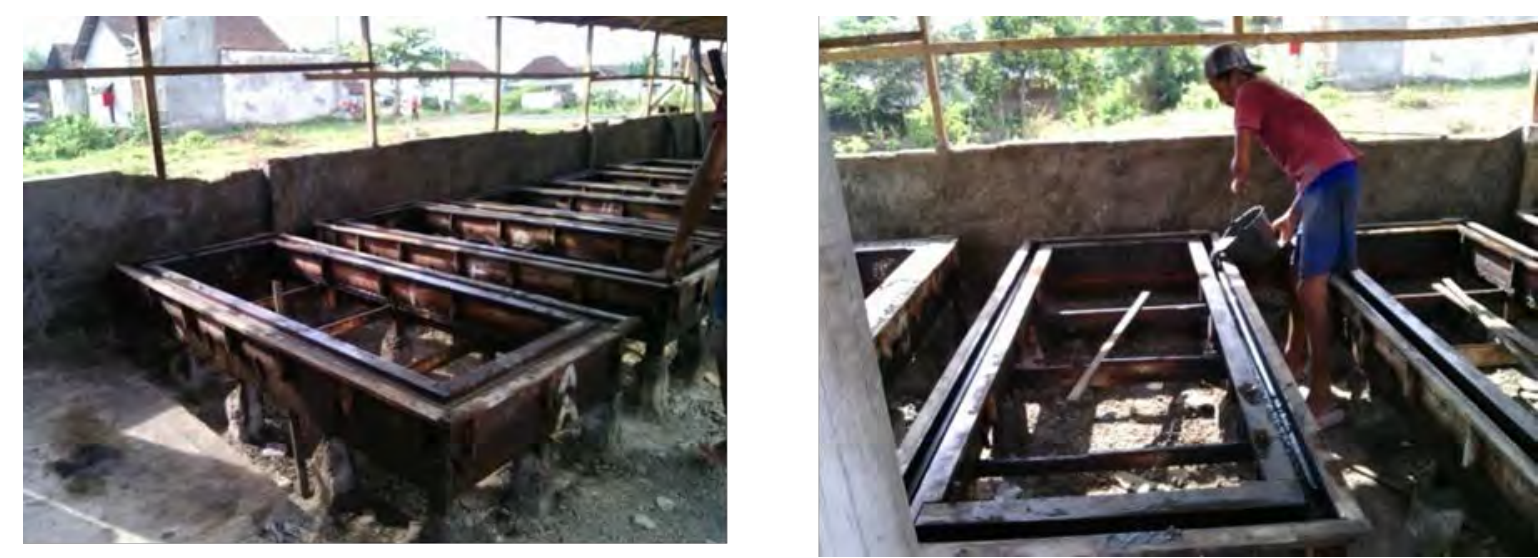

Gambar 5. Cetakan dan Proses Pengecoran Kusen Beton Sumber: Hasil survey pabrikasi kusen beton 
M. Shofi'ul Amin dkk, Pengaruh Limbah Asbes... 